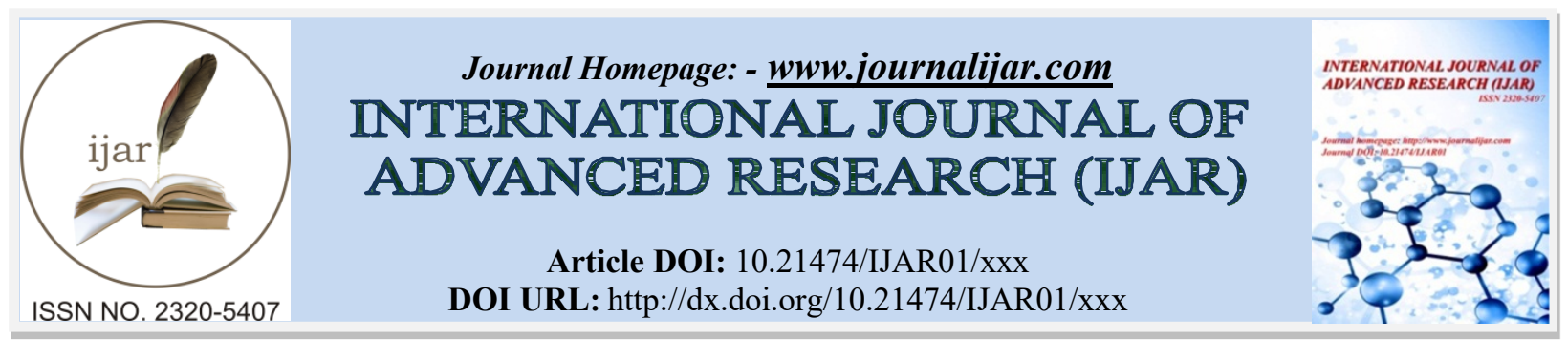

RESEARCH ARTICLE

\title{
THE PATTERN OF NASOPHARYNGEAL CARCINOMA IN SAUDI ARABIA: A DESCRIPTIVE EPIDEMIOLOGICAL STUDY OF DATA FROM SAUDI CANCER REGISTRY 2002-2013.
}

\author{
Ibrahim G. Alghamdi ${ }^{1}$ and Ghanem M. Al-Ghamdi ${ }^{2}$.
}

1. University of Al-Baha, College of Applied Medical Sciences, Saudi Arabia.

2. University of Al-Baha, College of Science, Saudi Arabia.

\section{Manuscript Info}

-.........................

Manuscript History

Received: 20 July 2017

Final Accepted: 22 August 2017

Published: September 2017

Key words:-

Cancer epidemiology; Nasopharyngeal carcinoma; Saudi Arabia; Age-adjusted Incidence rate.

\section{Abstract}

This study describes the epidemiological data of nasopharyngeal carcinoma (NPC) cases diagnosed from 2002 to 2013 among male and female Saudis, including crude incidence rate (CIR) and age-adjusted incidence rate stratified by age group, region, gender, and year of diagnosis. It is an epidemiological analysis of all NPC cases registered in the Saudi Cancer Registry (SCR) from 2002 to 2013. The statistical analyses were performed using parametric test to identify the significant differences between regions and genders, with focusing on the overall CIR and age-adjusted incidence rate stratified by region, gender, and year of diagnosis. The region of Qassim had the highest overall age-adjusted incidence rate of NPC among male Saudis from 2002 to 2013. While, the region of Jouf had the highest overall ageadjusted incidence rate of NPC among female Saudis from 2002 to 2013. In addition, the region of Jazan had the lowest overall ageadjusted incidence rate of NPC among male and female Saudis from 2002 to 2013. The age groups within the range of (60-74 and 45-59) were highest affected by NPC among both genders. However, the ageadjusted incidence rates of NPC were significantly higher in Saudi male than in female with approximately ratio of 2:1. This study revealed that the region of Qassim is the best geographic area in Saudi Arabia to study the major risk factors of NPC among male Saudis. While, the region of Jouf is the best geographic area to study the major risk factors of NPC among female Saudis. Furthermore, the region of Jazan is the best geographic area in Saudi Arabia to study the most important protective factors of NPC among male and female Saudis.

Copy Right, IJAR, 2017,. All rights reserved.

\section{Introduction:-}

Nasopharyngeal carcinoma (NPC) is a rare malignancy in many countries of the world, with an estimated ageadjusted incidence rate less than 1 per 100,000 population. ${ }^{1-2}$ The prevalence of NPC is very high in South China, with an estimated 20 to 40 cases per 100,000 population. ${ }^{3}$ The incidence rates of NPC are also observed higher in some countries of Southeast Asia, such as Singapore (15 per 100,000 population), Malaysia (9.7 per 100,000), and

Corresponding Author:- Ibrahim G. Alghamdi.

Address:- University of Al-Baha, College of Applied Medical Sciences, Saudi Arabia. 
Philippines (6.4 per 100,000). ${ }^{4}$ In addition, the country of Kenya is the highest area affected by NPC in Africa, with an estimated incidence rate (5.4 per 100,000 population). ${ }^{4}$

There are many epidemiological studies have reported several risk factors of NPC which included gender, ethnicity, certain type of diet, infection with Epstein-Barr virus (EBV), genetic factors and family history. The incidence of NPC is approximately twice in males than in females, while the most common geographic area affected by NPC is Southern China. In addition, eating diets with high salt cured fish and meat may contribute to increase the incidence rate of NPC. The relationship between EBV infection and NPC is not clear, since the world's population has been infected with this virus and the NPC is rare. Furthermore, some studies have shown that the genetic factors through certain inherited tissue types are a risk factor of developing NPC. However, family history through inherited genes has not been confirmed as a risk factor for NPC. ${ }^{5}$

In Saudi Arabia, the International Agency for Research on Cancer estimated that the age-adjusted incidence rate of NPC among male and female Saudis was 1.3 per 100,000 population in 2012, and the age-adjusted mortality rates was 0.7 per 100,000 population..$^{6-7}$ The purpose of this study is to describe the pattern of NPC among male and female Saudis from 2002 to 2013, with focusing on the CIR and age-adjusted incidence rate, stratified by gender, region, and year of diagnosis. However, we were very excited to study the epidemiological pattern of the NPC in Saudi Arabia, because, in fact, it is a living experience and suffering for the second author.

\section{Materials and methods:-}

This is a retrospective descriptive epidemiological study of all NPC cases in the Saudi population diagnosed from 2002 to 2013. The data is reported and managed by the Saudi Cancer Registry (SCR), which is a population based cancer registry that was established by the Ministry of Health in 1994. However, the most recent available dataset from the SCR was in 2013. Based on the annual Saudi cancer reports, there are a huge data for 13 administrative regions from 2002 to 2013 that describe the CIR and age-adjusted incidence rate, stratified by the provinces of Saudi Arabia, age group, gender of cases and year of diagnosis. The overall CIRs and age-adjusted incidence rates of NPC were calculated from 2002 to 2013. Furthermore, the significant differences in age-adjusted incidence rate of NPC among genders and regions, were statistically tested by using the Statistical Package for Social Sciences (SPSS) version 20.0 (IBM Corporation, Armonk, NY, USA).

\section{Results:-}

\section{The Pattern of Nasopharyngeal Carcinoma in the region of Asir and Baha:}

A total of 128 NPC cases were documented in the region of Asir by the SCR from 2002 to 2013. The overall CIRs of NPC among male and female Saudis living in Asir from 2002 to 2013 per 100,000 persons, were estimated at (1.0 and 0.5 Per 100,000 male/female). In addition, the overall age-adjusted incidence rates of NPC among male and female were estimated at (1.5 and 0.6 Per 100,000 male/female). However, there were no statistically differences in the rates of NPC between the region of Asir and other provinces of Saudi Arabia, except the region of Qassim, (F $[12,143]=6.848$; P-Value $<0.05)$, among male Saudis $(95 \%$ CI: $-2.4-0.5)$. 
A total of 21 NPC cases were documented in the region of Baha by the SCR from 2002 to 2013. The overall CIRs of NPC among male and female Saudis living in Baha from 2002 to 2013 per 100,000 persons, were estimated at (0.7 and 0.4 Per 100,000 male/female). In addition, the overall age-adjusted incidence rates of NPC among male and female were estimated at (1.0 and 0.5 Per 100,000 male/female). However, there were no statistically differences in the rates of NPC between the region of Baha and other provinces of Saudi Arabia, except the region of Qassim and Riyadh, $(\mathrm{F}[12,143]=6.848$; P-Value < 0.05), among male Saudis in Qassim (95\% CI: -2.4 - - 0.5), and in Riyadh (95\% CI: $-2.6--0.2)$ (Table 1).

\begin{tabular}{|c|c|c|c|c|c|c|c|c|c|c|c|c|}
\hline & \multicolumn{6}{|c|}{ Asir } & \multicolumn{6}{|c|}{ Baha } \\
\hline & \multicolumn{2}{|c|}{ No of Cases } & \multicolumn{2}{|l|}{ CIR } & \multicolumn{2}{|c|}{$\begin{array}{l}\text { Age-adjusted } \\
\text { incidence rate }\end{array}$} & \multicolumn{2}{|c|}{ No of Cases } & \multicolumn{2}{|l|}{ CIR } & \multicolumn{2}{|c|}{$\begin{array}{l}\text { Age-adjusted } \\
\text { incidence rate }\end{array}$} \\
\hline & Male & Female & Male & Female & Male & Female & Male & Female & Male & Female & Male & Female \\
\hline 2013 & 6 & 1 & 0.7 & 0.1 & 0.8 & 0.1 & 0 & 1 & 0.0 & 0.5 & 0.0 & 0.7 \\
\hline 2012 & 9 & 7 & 1.1 & 0.8 & 1.7 & 1.1 & 0 & 1 & 0.0 & 0.5 & 0.0 & 0.7 \\
\hline 2011 & 6 & 5 & 0.7 & 0.6 & 1.0 & 0.7 & 1 & 0 & 0.6 & 0.0 & 0.6 & 0.0 \\
\hline 2010 & 11 & 7 & 1.4 & 0.9 & 1.9 & 1.1 & 1 & 0 & 0.6 & 0.0 & 1.1 & 0.0 \\
\hline 2009 & 4 & 1 & 0.5 & 0.1 & 0.6 & 0.1 & 3 & 2 & 1.8 & 1.1 & 2.6 & 1.4 \\
\hline 2008 & 6 & 2 & 0.8 & 0.3 & 1.1 & 0.4 & 1 & 0 & 0.6 & 0.0 & 0.5 & 0.0 \\
\hline 2007 & 5 & 2 & 0.7 & 0.3 & 1.0 & 0.4 & 0 & 1 & 0.0 & 0.6 & 0.0 & 0.8 \\
\hline 2006 & 7 & 2 & 1.0 & 0.3 & 1.1 & 0.2 & 1 & 1 & 0.6 & 0.6 & 0.8 & 0.9 \\
\hline 2005 & 9 & 2 & 1.3 & 0.8 & 1.9 & 0.4 & 2 & 2 & 1.3 & 1.1 & 1.4 & 1.3 \\
\hline 2004 & 9 & 4 & 1.3 & 0.5 & 2.3 & 0.9 & 2 & 0 & 1.3 & 0.0 & 2.3 & 0.0 \\
\hline 2003 & 12 & 2 & 1.8 & 0.3 & 3.1 & 0.4 & 0 & 0 & 0.0 & 0.0 & 0.0 & 0.0 \\
\hline 2002 & 5 & 4 & 0.8 & 0.6 & 1.4 & 1.2 & 2 & 0 & 1.4 & 0.0 & 3.0 & 0.0 \\
\hline Overall & 7 & 3 & 1.0 & 0.5 & 1.5 & 0.6 & 1.1 & 0.7 & 0.7 & 0.4 & 1.0 & 0.5 \\
\hline Total & 89 & 39 & & & & & 13 & 8 & & & & \\
\hline
\end{tabular}

Table 1:- The overall CIR and age-adjusted incidence rate of nasopharyngeal carcinoma among male and female Saudis in the region of Asir and Baha, from 2002 to 2013.

\section{The Pattern of Nasopharyngeal Carcinoma in the region of Jazan and Najran:}

A total of 49 NPC cases were documented in the region of Jazan by the SCR from 2002 to 2013. The overall CIRs of NPC among male and female Saudis living in Jazan from 2002 to 2013 per 100,000 persons, were estimated at (0.5 and 0.3 Per 100,000 male/female). In addition, the overall age-adjusted incidence rates of NPC among male and female were estimated at (0.6 and 0.4 Per 100,000 male/female). Furthermore, the region of Jazan recorded the lowest rates of NPC among male and female in Saudi Arabia. However, there were no statistically differences in the rates of NPC among the region of Jazan and other provinces of Saudi Arabia, except the region of Qassim and Riyadh, $(\mathrm{F}[12,143]=6.848$; P-Value < 0.05), among male Saudis in Qassim (95\% CI: $-3.2--0.9)$, and in Riyadh (95\% CI: $-3.0--0.6)$.

A total of 18 NPC cases were documented in the region of Najran by the SCR from 2002 to 2013. The overall CIRs of NPC among male and female Saudis living in Najran from 2002 to 2013 per 100,000 persons, were estimated at (0.6 and 0.2 Per 100,000 male/female). In addition, the overall age-adjusted incidence rates of NPC among male and female were estimated at (1.3 and 0.3 Per 100,000 male/female). However, there were no statistically differences in 
the rates of NPC between the region of Najran and other provinces of Saudi Arabia, except the region of Qassim and Riyadh, $(\mathrm{F}[12,143]=6.848$; P-Value < 0.05), among male Saudis in Qassim (95\% CI: -2.6 - - 0.2), and in Riyadh (95\% CI: -2.4 - - 0.1) (Table 2).

\begin{tabular}{|c|c|c|c|c|c|c|c|c|c|c|c|c|}
\hline & \multicolumn{6}{|c|}{ Jazan } & \multicolumn{6}{|c|}{ Najran } \\
\hline & \multicolumn{2}{|c|}{ No of Cases } & \multicolumn{2}{|l|}{ CIR } & \multicolumn{2}{|c|}{$\begin{array}{l}\text { Age-adjusted } \\
\text { incidence rate }\end{array}$} & \multicolumn{2}{|c|}{ No of Cases } & \multicolumn{2}{|l|}{ CIR } & \multicolumn{2}{|c|}{$\begin{array}{l}\text { Age-adjusted } \\
\text { incidence rate }\end{array}$} \\
\hline & Male & Female & Male & Female & Male & Female & Male & Female & Male & Female & Male & Female \\
\hline 2013 & 4 & 2 & 0.7 & 0.3 & 0.9 & 0.3 & 1 & 0 & 0.5 & 0.0 & 0.3 & 0.0 \\
\hline 2012 & 2 & 1 & 0.3 & 0.2 & 0.3 & 0.2 & 3 & 1 & 1.4 & 0.5 & 3.1 & 0.3 \\
\hline 2011 & 3 & 0 & 0.5 & 0.0 & 0.7 & 0.0 & 2 & 0 & 1.0 & 0.0 & 1.4 & 0.0 \\
\hline 2010 & 5 & 1 & 0.9 & 0.2 & 1.0 & 0.2 & 1 & 0 & 0.5 & 0.0 & 1.2 & 0.0 \\
\hline 2009 & 2 & 0 & 0.4 & 0.0 & 0.6 & 0.0 & 1 & 0 & 0.5 & 0.0 & 1.2 & 0.0 \\
\hline 2008 & 5 & 1 & 1.0 & 0.2 & 1.3 & 0.2 & 0 & 2 & 0.0 & 1.0 & 0.0 & 2.4 \\
\hline 2007 & 3 & 2 & 0.6 & 0.4 & 0.6 & 0.5 & 1 & 0 & 0.5 & 0.0 & 0.8 & 0.0 \\
\hline 2006 & 3 & 1 & 0.6 & 0.2 & 0.7 & 0.3 & 2 & 0 & 1.1 & 0.0 & 2.5 & 0.0 \\
\hline 2005 & 4 & 0 & 0.8 & 0.0 & 1.4 & 0.0 & 0 & 0 & 0.0 & 0.0 & 0.0 & 0.0 \\
\hline 2004 & 0 & 3 & 0.0 & 0.6 & 0.0 & 0.8 & 1 & 0 & 0.6 & 0.0 & 0.5 & 0.0 \\
\hline 2003 & 0 & 2 & 0.0 & 0.4 & 0.0 & 0.6 & 0 & 1 & 0.0 & 0.6 & 0.0 & 1.0 \\
\hline 2002 & 0 & 5 & 0.0 & 1.0 & 0.0 & 1.1 & 2 & 0 & 1.2 & 0.0 & 4.0 & 0.0 \\
\hline Overall & 2.6 & 1.5 & 0.5 & 0.3 & 0.6 & 0.4 & 1.2 & 0.3 & 0.6 & 0.2 & 1.3 & 0.3 \\
\hline Total & 31 & 18 & & & & & 14 & 4 & & & & \\
\hline
\end{tabular}

Table 2:- The overall CIR and age-adjusted incidence rate of nasopharyngeal carcinoma among male and female Saudis in the region of Jazan and Najran, from 2002 to 2013.

\section{The Pattern of Nasopharyngeal Carcinoma in the region of Hail and Qassim:}

A total of 34 NPC cases were documented in the region of Hail by the SCR from 2002 to 2013. The overall CIRs of NPC among male and female Saudis living in Hail from 2002 to 2013 per 100,000 persons, were estimated at (0.7 and 0.5 Per 100,000 male/female). In addition, the overall age-adjusted incidence rates of NPC among male and female were estimated at ( 0.9 and 0.7 Per 100,000 male/female). However, there were no statistically differences in the rates of NPC between the region of Hail and other provinces of Saudi Arabia, except the region of Qassim, and Riyadh $(\mathrm{F}[12,143]=6.848$; P-Value < 0.05), among male Saudis in Qassim (95\% CI: -3.0 - 0.6), and in Riyadh (95\% CI: $-2.7-0.4)$.

A total of 139 NPC cases were documented in the region of Qassim by the SCR from 2002 to 2013. The overall CIRs of NPC among male and female Saudis living in Qassim from 2002 to 2013 per 100,000 persons, were estimated at (1.9 and 0.7 Per 100,000 male/female). In addition, the overall age-adjusted incidence rates of NPC among male and female were estimated at (2.7 and 1.0 Per 100,000 male/female). Furthermore, the region of Qassim recorded the highest rate of NPC among male in Saudi Arabia. However, there were statistically differences in the rates of NPC between the region of Qassim and other provinces of Saudi Arabia, except the region of Madinah, Riyadh, Makkah, and eastern region $(\mathrm{F}[12,143]=6.848$; P-Value $>0.05)$, among male Saudis in Madinah (95\% CI: $0.1-2.3)$, in Riyadh (95\% CI: $0.1-1.4)$, in Makkah (95\% CI: $0.2-2.1)$, and in eastern region (95\% CI:

\section{2 - 2.2) (Table 3).}




\begin{tabular}{|c|c|c|c|c|c|c|c|c|c|c|c|c|}
\hline & \multicolumn{6}{|c|}{ Hail } & \multicolumn{6}{|c|}{ Qassim } \\
\hline & \multicolumn{2}{|c|}{ No of Cases } & \multicolumn{2}{|l|}{ CIR } & \multicolumn{2}{|c|}{$\begin{array}{l}\text { Age-adjusted } \\
\text { incidence rate }\end{array}$} & \multicolumn{2}{|c|}{ No of Cases } & \multicolumn{2}{|l|}{ CIR } & \multicolumn{2}{|c|}{$\begin{array}{l}\text { Age-adjusted } \\
\text { incidence rate }\end{array}$} \\
\hline & Male & Female & Male & Female & Male & Female & Male & Female & Male & Female & Male & Female \\
\hline 2013 & 4 & 1 & 1.5 & 0.4 & 2.0 & 0.6 & 14 & 3 & 2.8 & 0.6 & 3.1 & 1.0 \\
\hline 2012 & 0 & 0 & 0.0 & 0.0 & 0.0 & 0.0 & 9 & 3 & 1.8 & 0.6 & 2.5 & 0.8 \\
\hline 2011 & 3 & 0 & 1.2 & 0.0 & 1.6 & 0.0 & 9 & 3 & 1.9 & 0.6 & 2.2 & 0.8 \\
\hline 2010 & 2 & 0 & 0.8 & 0.0 & 1.0 & 0.0 & 10 & 2 & 2.1 & 0.4 & 3.1 & 0.3 \\
\hline 2009 & 1 & 0 & 0.4 & 0.0 & 0.7 & 0.0 & 9 & 4 & 2 & 0.9 & 2.6 & 1.8 \\
\hline 2008 & 0 & 1 & 0.0 & 0.4 & 0.0 & 0.4 & 9 & 3 & 2.0 & 0.7 & 3.0 & 0.9 \\
\hline 2007 & 2 & 0 & 0.9 & 0.0 & 1.0 & 0.0 & 9 & 7 & 2.1 & 1.6 & 2.8 & 2.0 \\
\hline 2006 & 0 & 5 & 0.0 & 2.1 & 0.0 & 2.8 & 8 & 2 & 1.9 & 0.5 & 2.5 & 1.1 \\
\hline 2005 & 3 & 0 & 1.3 & 0.0 & 1.7 & 0.0 & 6 & 3 & 0.8 & 0.4 & 1.3 & 0.7 \\
\hline 2004 & 3 & 0 & 1.4 & 0.0 & 1.6 & 0.0 & 5 & 4 & 1.2 & 1.0 & 1.9 & 1.7 \\
\hline 2003 & 1 & 5 & 0.5 & 2.2 & 0.6 & 2.8 & 6 & 1 & 1.5 & 0.3 & 3.4 & 0.4 \\
\hline 2002 & 1 & 2 & 0.5 & 0.9 & 0.6 & 1.7 & 8 & 2 & 2.1 & 0.5 & 4.3 & 0.5 \\
\hline Overall & 1.7 & 1.2 & 0.7 & 0.5 & 0.9 & 0.7 & 8.5 & 3.1 & 1.9 & 0.7 & 2.7 & 1.0 \\
\hline Total & 20 & 14 & & & & & 102 & 37 & & & & \\
\hline
\end{tabular}

Table 3:- The overall CIR and age-adjusted incidence rate of nasopharyngeal carcinoma among male and female Saudis in the region of Hail and Qassim, from 2002 to 2013.

The Pattern of Nasopharyngeal Carcinoma in the region of Madinah and Jouf:

A total of 132 NPC cases were documented in the region of Madinah by the SCR from 2002 to 2013. The overall CIRs of NPC among male and female Saudis living in Madinah from 2002 to 2013 per 100,000 persons, were estimated at (1.1 and 0.6 Per 100,000 male/female). In addition, the overall age-adjusted incidence rates of NPC among male and female were estimated at (1.6 and 0.9 Per 100,000 male/female). However, there were no statistically differences in the rates of NPC between the region of Madinah and other provinces of Saudi Arabia, except the region of Qassim, and Riyadh, P-Value $>0.05$.

A total of 44 NPC cases were documented in the region of Jouf by the SCR from 2002 to 2013. The overall CIRs of NPC among male and female Saudis living in Jouf from 2002 to 2013 per 100,000 persons, were estimated at (1.2 and 0.9 Per 100,000 male/female). In addition, the overall age-adjusted incidence rates of NPC among male and female were estimated at (2.2 and 1.6 Per 100,000 male/female). Furthermore, the region of Jouf recorded the highest rate of NPC among female in Saudi Arabia. However, there were no statistically differences in the rates of NPC between the region of Jouf and other provinces of Saudi Arabia, except the region of Baha, Jazan, Najran, and eastern region $(\mathrm{F}[12,143]=6.848$; P-Value < 0.05), among female Saudis in Baha (95\% CI: 0.07 - 2.1), in Jazan (95\% CI: $0.2-2.2$ ), in Najran (95\% CI: $0.2-2.2)$, and in eastern region (95\% CI: $0.1-2.0)$ (Table 4).

\begin{tabular}{|c|c|c|c|c|c|c|c|c|c|c|c|c|}
\hline & \multicolumn{6}{|c|}{ Madinah } & \multicolumn{6}{|c|}{ Jouf } \\
\hline & \multicolumn{2}{|c|}{ No of Cases } & \multicolumn{2}{|c|}{ CIR } & \multicolumn{2}{|c|}{$\begin{array}{l}\text { Age-adjusted } \\
\text { incidence rate }\end{array}$} & \multicolumn{2}{|c|}{ No of Cases } & \multicolumn{2}{|c|}{ CIR } & \multicolumn{2}{|c|}{$\begin{array}{l}\text { Age-adjusted } \\
\text { incidence rate }\end{array}$} \\
\hline & Male & Female & Male & Female & Male & Female & Male & Female & Male & Female & Male & Female \\
\hline 2013 & 11 & 8 & 1.6 & 1.2 & 2.4 & 1.7 & 2 & 4 & 1.0 & 2.1 & 2.0 & 3.4 \\
\hline 2012 & 3 & 2 & 0.5 & 0.3 & 0.8 & 0.5 & 4 & 0 & 2.1 & 0.0 & 3.0 & 0.0 \\
\hline 2011 & 6 & 5 & 0.9 & 0.8 & 1.4 & 1.4 & 2 & 4 & 1.1 & 2.2 & 2.2 & 3.6 \\
\hline 2010 & 15 & 4 & 2.4 & 0.6 & 3.0 & 0.8 & 3 & 0 & 1.7 & 0.0 & 2.1 & 0.0 \\
\hline
\end{tabular}




\begin{tabular}{|l|l|l|l|l|l|l|l|l|l|l|l|l|}
\hline $\mathbf{2 0 0 9}$ & 3 & 3 & 0.5 & 0.5 & 0.8 & 0.8 & 2 & 1 & 1.2 & 0.6 & 2.1 & 1.2 \\
\hline $\mathbf{2 0 0 8}$ & 7 & 1 & 1.1 & 0.2 & 1.7 & 0.3 & 4 & 3 & 2.3 & 1.8 & 3.9 & 2.2 \\
\hline $\mathbf{2 0 0 7}$ & 7 & 5 & 1.1 & 0.8 & 1.6 & 1.1 & 0 & 3 & 0.0 & 1.9 & 0.0 & 3.9 \\
\hline $\mathbf{2 0 0 6}$ & 10 & 6 & 1.7 & 1.0 & 2.4 & 1.2 & 2 & 0 & 1.2 & 0.0 & 2.5 & 0.0 \\
\hline $\mathbf{2 0 0 5}$ & 6 & 3 & 0.4 & 0.2 & 0.8 & 0.4 & 2 & 0 & 1.3 & 0.0 & 2.9 & 0.0 \\
\hline $\mathbf{2 0 0 4}$ & 6 & 4 & 1.1 & 0.7 & 1.9 & 1.2 & 3 & 1 & 1.9 & 0.6 & 2.7 & 1.5 \\
\hline $\mathbf{2 0 0 3}$ & 4 & 7 & 0.7 & 1.2 & 1.3 & 1.7 & 0 & 1 & 0.0 & 0.7 & 0.0 & 0.8 \\
\hline $\mathbf{2 0 0 2}$ & 6 & 0 & 1.1 & 0.0 & 1.6 & 0.0 & 1 & 2 & 0.7 & 1.4 & 2.8 & 2.0 \\
\hline Overall & 7 & 4 & 1.1 & 0.6 & 1.6 & 0.9 & 2.1 & 1.6 & 1.2 & 0.9 & 2.2 & $\mathbf{1 . 6}$ \\
\hline Total & 84 & 48 & & & & & 25 & 19 & & & & \\
\hline
\end{tabular}

Table 4:- The overall CIR and age-adjusted incidence rate of nasopharyngeal carcinoma among male and female Saudis in the region of Madinah and Jouf, from 2002 to 2013.

The Pattern of Nasopharyngeal Carcinoma in the region of Tabuk and Northern Region:

A total of 55 NPC cases were documented in the region of Tabuk by the SCR from 2002 to 2013. The overall CIRs of NPC among male and female Saudis living in Tabuk from 2002 to 2013 per 100,000 persons, were estimated at (0.9 and 0.5 Per 100,000 male/female). In addition, the overall age-adjusted incidence rates of NPC among male and female were estimated at (1.7 and 0.9 Per 100,000 male/female). However, there were no statistically differences in the rates of NPC between the region of Tabuk and other provinces of Saudi Arabia, P-Value $>0.05$.

A total of 16 NPC cases were documented in the northern region by the SCR from 2002 to 2013. The overall CIRs of NPC among male and female Saudis living in the northern region from 2002 to 2013 per 100,000 persons, were estimated at ( 0.5 and 0.5 Per 100,000 male/female). In addition, the overall age-adjusted incidence rates of NPC among male and female were estimated at ( 0.8 and 0.8 Per 100,000 male/female). However, there were no statistically differences in the rates of NPC between the northern region and other provinces of Saudi Arabia, except the region of Qassim and Riyadh (F [12,143] = 6.848; P-Value < 0.05), among male Saudis in Qassim (95\% CI: -3.1 $--0.7)$, and in Riyadh (95\% CI: $-2.9--0.5)$ (Table 5).

\begin{tabular}{|c|c|c|c|c|c|c|c|c|c|c|c|c|}
\hline & \multicolumn{6}{|c|}{ Tabuk } & \multicolumn{6}{|c|}{ Northern Region } \\
\hline & \multicolumn{2}{|c|}{ No of Cases } & \multicolumn{2}{|l|}{ CIR } & \multicolumn{2}{|c|}{$\begin{array}{l}\text { Age-adjusted } \\
\text { incidence rate }\end{array}$} & \multicolumn{2}{|c|}{ No of Cases } & \multicolumn{2}{|l|}{ CIR } & \multicolumn{2}{|c|}{$\begin{array}{l}\text { Age-adjusted } \\
\text { incidence rate }\end{array}$} \\
\hline & Male & Female & Male & Female & Male & Female & Male & \begin{tabular}{|l|} 
Female \\
\end{tabular} & Male & Female & Male & Female \\
\hline 2013 & 6 & 2 & 1.6 & 0.6 & 3.7 & 0.5 & 2 & 3 & 1.4 & 2.0 & 1.9 & 2.8 \\
\hline 2012 & 2 & 3 & 0.6 & 0.9 & 0.6 & 1.1 & 0 & 0 & 0.0 & 0.0 & 0.0 & 0.0 \\
\hline 2011 & 5 & 0 & 1.4 & 0.0 & 3.1 & 0.0 & 1 & 0 & 0.7 & 0.0 & 0.6 & 0.0 \\
\hline 2010 & 3 & 1 & 0.9 & 0.3 & 1.7 & 0.5 & 0 & 1 & 0.0 & 0.7 & 0.0 & 1.4 \\
\hline 2009 & 1 & 2 & 0.3 & 0.6 & 1.1 & 1.5 & 0 & 1 & 0.0 & 0.8 & 0.0 & 1.7 \\
\hline 2008 & 3 & 1 & 0.9 & 0.3 & 1.5 & 0.5 & 1 & 0 & 0.8 & 0.0 & 1.3 & 0.0 \\
\hline 2007 & 5 & 2 & 1.5 & 0.6 & 3.1 & 0.5 & 2 & 0 & 1.6 & 0.0 & 1.7 & 0.0 \\
\hline 2006 & 2 & 2 & 0.6 & 0.7 & 1.1 & 1.8 & 0 & 0 & 0.0 & 0.0 & 0.0 & 0.0 \\
\hline 2005 & 1 & 1 & 0.3 & 0.3 & 0.2 & 0.9 & 1 & 0 & 0.8 & 0.0 & 1.9 & 0.0 \\
\hline 2004 & 1 & 1 & 0.3 & 0.3 & 0.8 & 0.9 & 1 & 1 & 0.8 & 0.3 & 1.8 & 0.9 \\
\hline 2003 & 4 & 2 & 1.3 & 0.7 & 2.5 & 1.2 & 0 & 0 & 0.0 & 0.0 & 0.0 & 0.0 \\
\hline 2002 & 3 & 2 & 1.0 & 0.7 & 1.4 & 1.1 & 0 & 2 & 0.0 & 1.8 & 0.0 & 2.8 \\
\hline Overall & 3 & 1.6 & 0.9 & 0.5 & 1.7 & 0.9 & 0.7 & 0.7 & 0.5 & 0.5 & 0.8 & 0.8 \\
\hline Total & 36 & 19 & & & & & 8 & 8 & & & & \\
\hline
\end{tabular}

Table 5:- The overall CIR and age-adjusted incidence rate of nasopharyngeal carcinoma among male and female Saudis in the region of Tabuk and Northern region, from 2002 to 2013. 


\section{The Pattern of Nasopharyngeal Carcinoma in the region of Riyadh and Makkah:}

A total of 539 NPC cases were documented in the region of Riyadh by the SCR from 2002 to 2013 . The overall CIRs of NPC among male and female Saudis living in Riyadh from 2002 to 2013 per 100,000 persons, were estimated at (1.6 and 0.6 Per 100,000 male/female). In addition, the overall age-adjusted incidence rates of NPC among male and female were estimated at (2.5 and 0.9 Per 100,000 male/female). However, there were statistically differences in the rates of NPC between the region of Riyadh and other provinces that mentioned in the above results, $\mathrm{P}-$ Value $<0.05$.

A total of 403 NPC cases were documented in the region of Makkah by the SCR from 2002 to 2013 . The overall CIRs of NPC among male and female Saudis living in the Makkah from 2002 to 2013 per 100,000 persons, were estimated at (1.2 and 0.5 Per 100,000 male/female). In addition, the overall age-adjusted incidence rates of NPC among male and female were estimated at (1.8 and 0.6 Per 100,000 male/female). However, there were no statistically differences in the rates of NPC between the northern region and other provinces in Saudi Arabia, PValue $>0.05$ (Table 6).

\begin{tabular}{|c|c|c|c|c|c|c|c|c|c|c|c|c|}
\hline & \multicolumn{6}{|c|}{ Riyadh } & \multicolumn{6}{|c|}{ Makkah } \\
\hline & \multicolumn{2}{|c|}{ No of Cases } & \multicolumn{2}{|l|}{ CIR } & \multicolumn{2}{|c|}{$\begin{array}{l}\text { Age-adjusted } \\
\text { incidence rate }\end{array}$} & \multicolumn{2}{|c|}{ No of Cases } & \multicolumn{2}{|c|}{ CIR } & \multicolumn{2}{|c|}{$\begin{array}{l}\text { Age-adjusted } \\
\text { incidence rate }\end{array}$} \\
\hline & Male & Female & Male & Female & Male & Female & Male & Female & Male & Female & Male & Female \\
\hline 2013 & 54 & 11 & 2.3 & 0.5 & 3.3 & 0.5 & 21 & 9 & 0.9 & 0.4 & 1.2 & 0.5 \\
\hline 2012 & 33 & 11 & 1.4 & 0.5 & 2.0 & 0.6 & 31 & 12 & 1.4 & 0.5 & 1.9 & 0.6 \\
\hline 2011 & 33 & 16 & 1.5 & 0.7 & 2.2 & 0.8 & 29 & 9 & 1.4 & 0.4 & 1.8 & 0.5 \\
\hline 2010 & 44 & 17 & 2.0 & 0.8 & 3.2 & 1.5 & 20 & 6 & 1.0 & 0.3 & 1.3 & 0.4 \\
\hline 2009 & 28 & 14 & 1.3 & 0.7 & 2.3 & 1.2 & 25 & 13 & 1.2 & 0.7 & 1.8 & 0.7 \\
\hline 2008 & 46 & 16 & 2.2 & 0.8 & 3.4 & 1.1 & 26 & 8 & 1.3 & 0.4 & 2.0 & 0.6 \\
\hline 2007 & 18 & 16 & 0.9 & 0.8 & 1.3 & 1.2 & 29 & 12 & 1.5 & 0.6 & 2.2 & 0.8 \\
\hline 2006 & 19 & 9 & 0.9 & 0.5 & 1.4 & 0.6 & 21 & 11 & 1.1 & 0.6 & 1.5 & 0.8 \\
\hline 2005 & 40 & 9 & 2.1 & 0.5 & 3.4 & 0.9 & 28 & 8 & 1.5 & 0.4 & 2.3 & 0.6 \\
\hline 2004 & 27 & 14 & 1.4 & 0.8 & 2.3 & 1.2 & 24 & 7 & 1.3 & 0.4 & 1.8 & 0.6 \\
\hline 2003 & 28 & 6 & 1.5 & 0.3 & 2.5 & 0.8 & 21 & 7 & 1.2 & 0.4 & 2.0 & 0.6 \\
\hline 2002 & 22 & 8 & 1.2 & 0.5 & 2.7 & 0.9 & 16 & 10 & 0.9 & 0.6 & 1.4 & 0.9 \\
\hline Overall & 32.7 & 12.3 & 1.6 & 0.6 & 2.5 & 0.9 & 24.3 & 9.3 & 1.2 & 0.5 & 1.8 & 0.6 \\
\hline Total & 392 & 147 & & & & & 291 & 112 & & & & \\
\hline
\end{tabular}

Table 6:- The overall CIR and age-adjusted incidence rate of nasopharyngeal carcinoma among male and female Saudis in the region of Riyadh and Makkah, from 2002 to 2013.

The Pattern of Nasopharyngeal Carcinoma in the eastern region of Saudi Arabia:

A total of 213 NPC cases were documented in the eastern region by the SCR from 2002 to 2013. The overall CIRs of NPC among male and female Saudis living in the eastern region from 2002 to 2013 per 100,000 persons, were estimated at (1.0 and 0.3 Per 100,000 male/female). In addition, the overall age-adjusted incidence rates of NPC among male and female were estimated at (1.7 and 0.5 Per 100,000 male/female). However, there were no statistically differences in the rates of NPC between the eastern region and other provinces, except the region of Jouf among female Saudis, the results mentioned in the above results, P-Value $<0.05$ (Table 7). 


\begin{tabular}{|c|c|c|c|c|c|c|}
\hline \multirow[b]{3}{*}{ Region } & \multicolumn{6}{|c|}{ Eastern Region } \\
\hline & \multicolumn{2}{|c|}{ No of Cases } & \multicolumn{2}{|c|}{ CIR Per 100,000 } & \multicolumn{2}{|c|}{$\begin{array}{c}\text { Age-adjusted incidence rate Per } \\
100,000\end{array}$} \\
\hline & Male & Female & Male & Female & Male & Female \\
\hline 2013 & 10 & 2 & 0.6 & 0.1 & 0.9 & 0.3 \\
\hline 2012 & 14 & 4 & 0.9 & 0.3 & 1.7 & 0.3 \\
\hline 2011 & 21 & 3 & 1.4 & 0.2 & 2.8 & 0.3 \\
\hline 2010 & 16 & 1 & 1.1 & 0.1 & 2.0 & 0.1 \\
\hline 2009 & 13 & 1 & 0.9 & 0.1 & 1.1 & 0.1 \\
\hline 2008 & 14 & 7 & 1.0 & 0.5 & 1.4 & 0.8 \\
\hline 2007 & 12 & 7 & 0.9 & 0.5 & 1.6 & 0.6 \\
\hline 2006 & 20 & 4 & 1.5 & 0.3 & 2.2 & 0.5 \\
\hline 2005 & 11 & 4 & 0.8 & 0.3 & 1.8 & 0.5 \\
\hline 2004 & 16 & 6 & 1.2 & 0.5 & 2.8 & 1.0 \\
\hline 2003 & 8 & 5 & 0.6 & 0.4 & 1.2 & 0.4 \\
\hline 2002 & 10 & 4 & 0.8 & 0.3 & 1.0 & 0.5 \\
\hline Overall & 13.8 & 4 & 1.0 & 0.3 & 1.7 & 0.5 \\
\hline Total & 165 & 48 & & & & \\
\hline
\end{tabular}

Table 7:- The overall CIR and age-adjusted incidence rate of nasopharyngeal carcinoma among male and female Saudis in the Eastern region, from 2002 to 2013.

The overall age specific incidence rate of NPC by gender was calculated from the SCR from 2002 to 2013. Males Saudis aged 60-74 and 45-59 years were most frequently diagnosed with NPC with an estimated overall age specific incidence rates of (18.3 and 14.2 Per 100,000 Male), while females Saudis aged 60-74 and 45-59 years were very similar in the overall age specific incidence rates of NPC with an estimated at (5.9 and 5.2 Per 100,000 Female) (Table 8). However, the ratio of male to female was 2:1, while the age-adjusted incidence rates of NPC were significantly higher in Saudi male than in female $(\mathrm{t}[310,285.4]=8.000, \mathrm{P}-$ Value $<0.001)$.

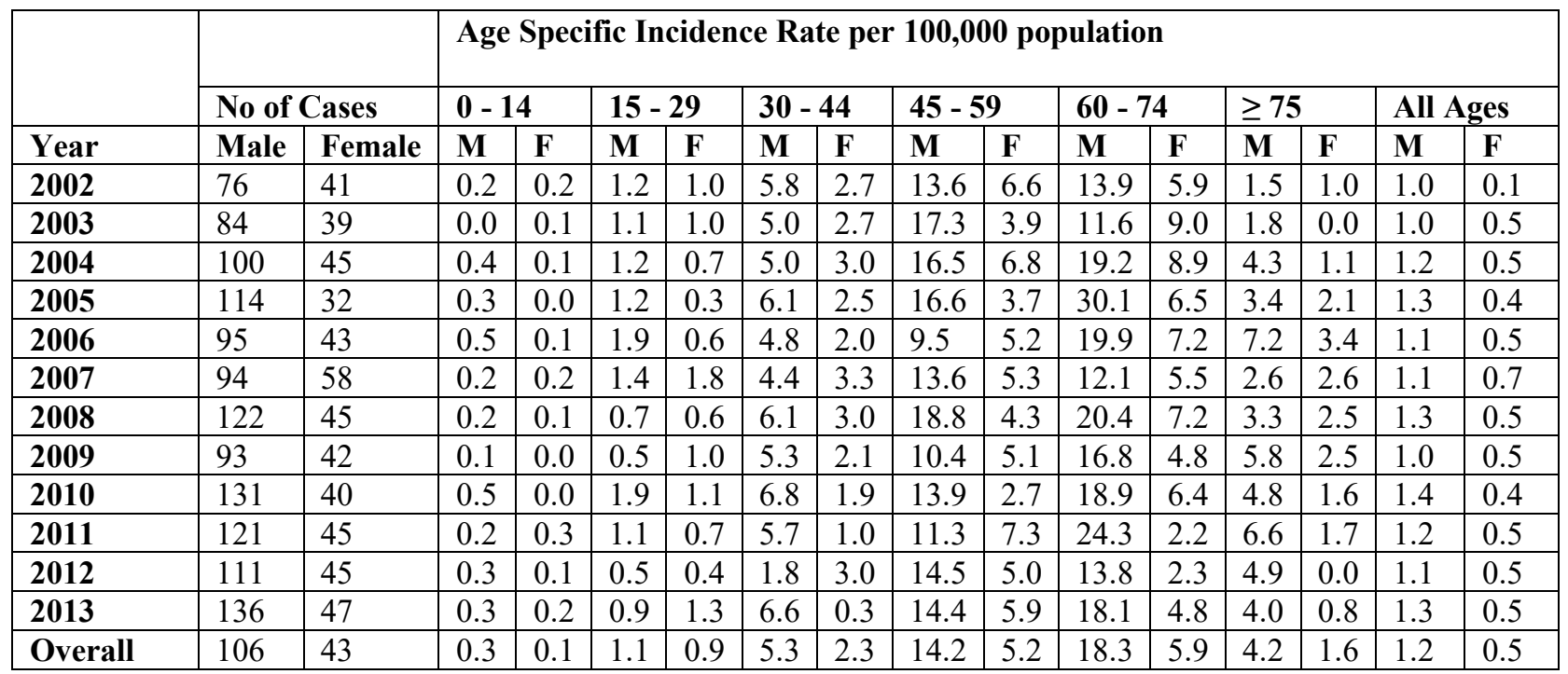

Table 8:- The overall age specific incidence rate of nasopharyngeal carcinoma among male and female Saudis from 2002 to 2013. 


\section{Discussion:-}

This is a descriptive epidemiological study of NPC among males and females Saudis from 2002 to 2013. It explores the pattern of NPC in all regions of Saudi Arabia, with focusing on the frequency number of cases, the CIR, and age-adjusted incidence rate stratified by gender, region, and year of diagnosis. The result of the study is based on the data recorded in the SCR from 2002 to 2013.

In this study, we have observed that the highest overall age-adjusted incidence rates of NPC among male Saudis were documented in the region of Qassim from 2002 to 2013. The most likely reason for this rising age-adjusted incidence rate is that most male Saudis living in the region of Qassim were more likely exposed to a specific risk factor that may less appear in other male Saudis living in other provinces of Saudi Arabia. However, two casecontrol studies should be conducted in the region of Qassim to identify the most important risk factors of NPC among male and female Saudis living in the region of Qassim. Figure 1, shows how one can identify the most important risk and protective factors for NPC among male and female Saudis living in the region of Qassim.

We have also observed that the highest overall age-adjusted incidence rates of NPC among female Saudis were documented in the region of Jouf from 2002 to 2013. The most likely reason for this rising age-adjusted incidence rate is that most female Saudis living in the region of Jouf were more likely exposed to a specific risk factor that may less appear in other female Saudis living in other provinces of Saudi Arabia. However, two case-control studies should be conducted in the region of Jouf to identify the most important risk factors of NPC among female and male Saudis living in the region of Jouf. Figure 2, shows how one can identify the most important risk and protective factors for NPC among female and male Saudis living in the region of Jouf.

From the above-mentioned result, it is very clear that the region of Jazan had the lowest overall age-adjusted incidence rates of NPC among male and female in Saudi Arabia, from 2002 to 2013. The most likely reason for this decreasing age-adjusted incidence rate is that most male and female Saudis living in the region of Jazan were more likely exposed to a specific protective factor that may does not appear in other male and female Saudis living in other provinces of Saudi Arabia. It means that the male and female Saudis living in the region of Jazan were sharing with each other the same protective factor of NPC. However, two case-control studies should be conducted in the region of Jazan to identify the most important protective factors of NPC among male and female Saudis living in the region of Jazan. Figure 3, shows how one can identify the most important risk and protective factors for NPC among male and female Saudis living in the region of Jazan. 
Figure 1

\section{Study Design in The Region of Qassim}

The overall age-adjusted incidence rates of NPC, from 2002 to 2013 were higher among male Saudis living in the region of Qassim, compared to other male Saudis living in other provinces of Saudi Arabia.

What is the reason behind that ??

The most likely reason for this rising age-adjusted incidence rate is that most male Saudis were more likely exposed to a specific risk factor that may less appear in other male Saudis living in other provinces of Saudi Arabia.

How one can identify this risk factor??

The risk factor can be identified by conducting two (2) Case-Control Studies among male and female Saudis living in the region of Qassim.

\section{Study (1)}

Case-Control Study for male Saudis
Study (2)

Case-Control Study for female Saudis

\section{Age Matching Process}

The probability of getting NPC is increasing with age, so it is very important to control the confounding variable of age.

The age of cases and controls should be very similar. For example, Age matched with an interval ( \pm 4 years)

Data collection and statistical analysis:

Conditional Logistic Regression Model for Matching Case-Control Study

\section{Results of the study}

The adjusted odds ratio should be calculated for all case-control studies to identify the risk and protective factors of NPC among male and female Saudis living in the region of Qassim.

It is very important to determin the highest risk factor of NPC among male and female Saudis living in the region of Qassim. This helps to identfy the major risk factor that male and Female Saudis are sharing with each other in the region of Qassim.

\section{Result (1)}

The highest risk factor of NPC among male Saudis in Qassim
Result (2)

The highest risk factor NPC among female Saudis in Qassim

Make comparisons between

2 Case-Control Studies

in the region of Qassim 
Figure 2

\section{Study Design in The Region of Jouf}

The overall age-adjusted incidence rates of NPC, from 2002 to 2013 were higher among female Saudis living in the region of Jouf, compared to other female Saudis living in other provinces of Saudi Arabia.

What is the reason behind that ??

The most likely reason for this rising age-adjusted incidence rate is that most female Saudis were more likely exposed to a specific risk factor that may less appear in other female Saudis living in other provinces of Saudi Arabia.

How one can identify this risk factor??

The risk factor can be identified by conducting two (2) Case-Control Studies among female and male Saudis living in the region of Jouf.

Study (1)

Case-Control Study for male Saudis
Study (2)

Case-Control Study for female Saudis

\section{Age Matching Process}

The probability of getting NPC is increasing with age, so it is very important to control the confounding variable of age.

The age of cases and controls should be very similar. For example, Age matched with an interval ( \pm 4 years )

Data collection and statistical analysis:

Conditional Logistic Regression Model for

Matching Case-Control Study

Results of the study

The adjusted odds ratio should be calculated for all case-control studies to identify the risk and protective factors of NPC among male and female Saudis living in the region of Jouf.

It is very important to determin the highest risk factor of NPC among male and female Saudis living in the region of Jouf. This helps to identfy the major risk factor that male and Female Saudis are sharing with each other in the region of Jouf.

\section{Result (1)}

The highest risk factor of NPC among female Saudis in Jouf
Result (2)

The highest risk factor of NPC among male Saudis in Jouf

\section{Make comparisons between \\ 2 Case-Control Studies}

in the region of Jouf 
Figure 3

\section{Study Design in The Region of Jazan}

The overall age-adjusted incidence rates of NPC, from 2002 to 2013 were the lowest among male and female Saudis living in the region of Jazan, compared to other male and female Saudis living in other provinces of Saudi Arabia.

What is the reason behind that??

The most likely reason for this decreasing age-adjusted incidence rate is that most male and female Saudis were more likely exposed to a specific protective factor that may does not appear in other male and female Saudis living in other provinces of Saudi Arabia.

How one can identify this risk factor??

The risk factor can be identified by conducting two (2) Case-Control Studies among male and female Saudis living in the region of Jazan.

Study (1)

Case-Control Study for male Saudis
Study (2)

Case-Control Study for female Saudis

\section{Age Matching Process}

The probability of getting NPC is increasing with age, so it is very important

to control the confounding variable of age.

The age of cases and controls should be very similar. For example, Age matched with an interval ( \pm 4 years )

Data collection and statistical analysis:

Conditional Logistic Regression Model for Matching Case-Control Study

\section{Results of the study}

The adjusted odds ratio should be calculated for all case-control studies to identify the protective factors of NPC among male and female Saudis living in the region of Jazan.

It is very important to determin the highest protective factor of NPC among male and female Saudis living in the region of Jazan. This helps to identfy the major protective factor that male and Female Saudis are sharing with each other in the region of Jazan.

\section{Result (1)}

The highest protective factor of NPC among male Saudis in Jazan
Result (2)

The highest protective factor of NPC among female Saudis in Jazan 


\section{Conclusion:-}

Our study revealed that the region Qassim is the best geographic area in Saudi Arabia to study the most important risk factors of NPC among male Saudis. While, the region of Jouf is the best geographic area in Saudi Arabia to study the most important risk factors of NPC among female Saudis. The region of Jazan had the lowest overall ageadjusted incidence rates of NPC among male and female in Saudi Arabia, from 2002 to 2013. Therefore, the secret for confirming the real protective factors of NPC can be found among male and female Saudis living in the region of Jazan. However, multiple case-control studies adjusted by gender and age should be conducted in the abovementioned regions to identify the major risk and protective factors of NPC.

\section{References:-}

1. Marlinda, A., Antonius, N.K., Arina, I.M., Averdi, R., Bambang, H., Soehartati, G., Bing, T., Jaap, M.M. 2012. Nasopharyngeal carcinoma in Indonesia: epidemiology, incidence, signs, and symptoms at presentation. Chinese Journal of Cancer., 31(4): 185-196.

2. Huang, D.P., Lo, K.W. Aetiological factors and pathogenesis. In: Gibb AG, editor. Nasopharyngeal Carcinoma. 2nd Ed. Hong Kong: The Chinese University Press; 1999. pp. 31-40.

3. Huang, T.B., Min, H.Q., Min, H.Q., Wang, H.M., Zhang, E.P., Hong, M.H., editors. Guangzhou: Guangdong Science and Technology Press; 1998. Nasopharyngeal Carcinoma Research; pp. 6-12.

4. Jeannel, D., Bouvier, G., Hubert, A. 1999. Nasopharyngeal carcinoma: an epidemiological approach to Carcinogenesis. Cancer Survey; 33:125-155

5. American Cancer Society. What are the risk factors for nasopharyngeal cancer, 2017. Available from: https://www.cancer.org/cancer/nasopharyngeal-cancer/causes-risks-prevention/risk-factors.html. Accessed July 28, 2017.

6. American Cancer Society. Global Cancer Facts and Figures. Estimated number of new cancer cases by world area, 2012. Available from: https://www.cancer.org/research/cancer-facts-statistics/global.html. Accessed July 25, 2017.

7. International Agency for Research on Cancer. GLOBOCAN. Estimated cancer incidence, mortality and prevalence worldwide in 2012. Available from: http://globocan.iarc.fr/Pages/summary_table_site_sel.aspx. Accessed July 25, 2017. 